\title{
Microinvasive Malignant Neoplasm
}

National Cancer Institute

\section{Source}

National Cancer Institute. Microinvasive Malignant Neoplasm. NCI Thesaurus. Code C36028.

A malignant neoplasm that has minimal stromal invasion. 